\title{
Left ventricular diastolic function in congenital myotonic dystrophy
}

\author{
F A Bu'Lock, M Sood, J V De Giovanni, S H Green
}

\begin{abstract}
Objective-Examination of left ventricular function and conduction abnormalities in myotonic dystrophy.

Design-Twelve patients (median age, 13.7 years) with myotonic dystrophy had detailed electrocardiography and echocardiography performed. Echocardiographic parameters were compared with body surface area (BSA) matched median normal values.

Results-Fractional shortening was slightly reduced (by 28-29\%) in three patients and three patients had mild mitral valve prolapse. Diastolic function was abnormal; isovolumic relaxation time (IVRT) and duration of early filling were prolonged compared with control values (median IVRT, $74 v 61 \mathrm{~ms}$ ). Peak E velocity was increased (median, $0.82 v 0.78 \mathrm{~m} / \mathrm{s}$ ) but atrial phase filling was normal. Heart rate was reduced (median, $68 v 81$ beats/ min). Conduction abnormalities were common but showed no clear relations with diastolic abnormalities.

Conclusions-Young patients with myotonic dystrophy have myocardial diastolic dysfunction as well as abnormal electrophysiology. The prognostic implications of such abnormalities require further study. (Arch Dis Child 1999;80:267-270)
\end{abstract}

Keywords: diastolic filling; myotonic dystrophy; Doppler echocardiography

Congenital myotonic dystrophy usually presents in the neonatal period as a congenital myopathy, with one or more of the following features: facial diplegia, hypotonia, respiratory problems, talipes, and delayed motor development. It is a multisystem disorder, now known to be caused by a gene abnormality on chromosome 19. The molecular defect has been traced recently to an unstable DNA triplet (a CDC sequence), and the untranslated end of the gene on the long arm of chromosome 19 is expanded. ${ }^{1}$

Myotonic dystrophy is inherited as an autosomal dominant condition, which is particularly severe when the mother is the transmitting parent, ${ }^{2}$ but it may not be diagnosed until later in childhood or, in its milder forms, in adult life. In later life, some patients manifest most of the classic features: myotonia, muscle atrophy, cardiac involvement, cataracts, frontal baldness, endocrine dysfunction, and mental retardation, whereas others may have few problems. $^{3}$
As with a number of skeletal muscle disorders, cardiac involvement is well described in adults. This is mainly manifest in disturbances of the conduction system, with first degree heart block, variable degrees of bundle branch block, and complete heart block being described. ${ }^{4}$ Such conduction abnormalities tend to be progressive, carry a risk of sudden death, and may require permanent pacemaker insertion ${ }^{67}$ during adulthood. Atrial $^{78}$ and ventricular tachyarrhythmias ${ }^{9} 10$ are also reported. Although dilated cardiomyopathy has been reported, ${ }^{511}$ systolic myocardial dysfunction appears to be less prominent than in other forms of muscular dystrophy. However, there are now a number of reports of cardiac decompensation during pregnancy ${ }^{12} 13$ and, together with the well recognised risks of anaesthesia, ${ }^{14}$ this suggests that more serious covert abnormalities may lie undetected. The highest infant mortality rate was described by Reardon et $a l,{ }^{15}$ who suggest that there is a $25 \%$ chance of death before 18 months of age, with only $50 \%$ of patients surviving until their mid-30s. Most of the deaths are attributed to respiratory causes and cardiac problems are rarely mentioned.

One of the most striking clinical characteristics of this disease in the older child and adult is the myotonia, caused by difficulty in relaxation of skeletal muscle, which has a characteristic electromyographic appearance. ${ }^{3}$ It is now well recognised that diastolic cardiac dysfunction (abnormalities of myocardial relaxation) may occur either in isolation from $^{16}$ or in association with ${ }^{17} 18$ systolic dysfunction. Indeed, diastolic abnormalities might even precede the development of systolic dysfunction in a number of progressive conditions. ${ }^{17}{ }^{19-21}$ Although overt myocardial myotonia is unlikely, more subtle diastolic dysfunction might well be present and clinically relevant. ${ }^{22}$ The presence of diastolic dysfunction might alert carers to the possibility of future systolic dysfunction and perhaps permit pre-emptive intervention in affected patients to avert catastrophic clinical decompensation. Diastolic function can be examined non-invasively in children using Doppler echocardiographic indices of transmitral flow, and size related normal values are now established. ${ }^{23}$

A group of young patients with congenital myotonic dystrophy without overt cardiac symptomatology underwent detailed cardiological assessment to attempt to identify and characterise any diastolic dysfunction and, if present, to determine any associations with other cardiac abnormalities. 
Table 1 Clinical and electrocardiographic details

\begin{tabular}{lllllllllll}
\hline $\begin{array}{l}\text { Age } \\
\text { (years })\end{array}$ & $\begin{array}{l}\text { Height } \\
(\mathrm{m})\end{array}$ & $\begin{array}{l}\text { Weight } \\
(\mathrm{kg})\end{array}$ & $\begin{array}{l}\mathrm{BSA} \\
\left(\mathrm{m}^{2}\right)\end{array}$ & $\begin{array}{l}\mathrm{SBP} \\
(\mathrm{mm} \mathrm{Hg})\end{array}$ & $\begin{array}{l}\mathrm{DBP} \\
(\mathrm{mm} \mathrm{Hg})\end{array}$ & $\begin{array}{l}\mathrm{P}-\mathrm{R} \\
(\mathrm{ms})\end{array}$ & $\begin{array}{l}\text { QRS } \\
(\mathrm{ms})\end{array}$ & $\begin{array}{l}\text { Min HR } \\
(\mathrm{bpm})\end{array}$ & $\begin{array}{l}\text { Max HR } \\
(\mathrm{bpm})\end{array}$ \\
\hline $\begin{array}{l}\text { Median } \\
\text { Range }\end{array}$ & 13.7 & 1.58 & 48.8 & 1.54 & 121 & 66 & 200 & 120 & 49 & 147 \\
& $5.0-31.4$ & $1.08-1.8$ & $17.5-84.5$ & $0.73-2.0$ & $96-148$ & $46-76$ & $160-340$ & $100-160$ & $32-72$ & $108-164$ \\
\hline
\end{tabular}

BSA, body surface area; SBP, systolic blood pressure; DBP, diastolic blood pressure; P-R, P-R interval; QRS, QRS duration from 12 lead ECG; MinHR, minimum heart rate on 24 hour Holter monitoring; MaxHR, maximum heart rate on 24 hour Holter monitoring; bpm, beats/min.

\section{Methods}

Of the 18 children and young adults with congenital myotonic dystrophy under the care of Birmingham Children's Hospital in 1994, 12 were able to attend for cardiac assessment. Aged between 5 and 31 (median, 13.7; mean, 16.6) years, there were seven male and five female patients. Diagnosis of myotonic dystrophy was based on history (including family history), clinical findings, electrophysiology, and DNA analysis. Five patients had been diagnosed in infancy. All had pronounced motor impairment but none had symptoms attributable to cardiovascular dysfunction. One patient was known to have a small secundum atrial septal defect (fossa ovalis defect) not requiring closure.

A full cardiovascular and echocardiographic examination was performed and a 12 lead electrocardiogram (ECG) was recorded on each patient, followed by 24 hour Holter monitoring. All examinations were performed and analysed by the same cardiologist (FAB).

Echocardiography was performed using a Hewlett Packard Sonos 500 ultrasound scanner with simultaneous ECG and phonocardiographic traces. Each study was recorded on to videotape for subsequent analysis using the predetermined protocol described previously. ${ }^{24}$

Left ventricular (LV) diastolic function was assessed from transmitral pulsed wave Doppler flow signals recorded with the Doppler sample volume positioned between the tips of the mitral valve leaflets. Isovolumic relaxation time (IVRT; ms); peak early and atrial phase filling velocities ( $\mathrm{E}$ and $\mathrm{A}$, respectively; $\mathrm{m} / \mathrm{s}$ ); EA ratio $(\mathrm{E} / \mathrm{A})$; time to, and duration of deceleration from peak $\mathrm{E}$ velocity (EAccT and EDecT, respectively; ms) were all measured and the mean values from five cardiac cycles were used for analysis. Left ventricular $M$ mode recordings were taken from the parasternal long axis view. Diastolic dimensions were measured at the point of maximum diastolic posterior deflection of the posterior wall. The means of the measurements from four cardiac cycles were used and the left ventricular shortening fraction (SF; \%) was calculated from the mean LV dimensions as: $\mathrm{SF}=\mathrm{LV}$ diastolic - systolic/ diastolic diameter $\times 100$.

CONTROL GROUP

Study parameters were compared with those obtained from 137 healthy children and young adults studied using identical techniques, ${ }^{23}{ }^{24}$ expressed as group median values for $0.2 \mathrm{~m}^{2}$ body surface area (BSA) intervals. The control group comprised 65 female and 72 male subjects aged between 2.4 months and 40 years (median, 7.25; mean, 8.68) with no evidence of heart disease according to history, physical, or echocardiographic criteria. Four had innocent murmurs. Matched median normal control values of all study parameters were determined for each patient on the basis of their BSA and were used for paired comparisons as described previously. $^{24}$

STATISTICAL TECHNIQUES

Paired comparisons with median BSA matched control data were performed using Wilcoxon's signed ranks tests (two tailed $\mathrm{p}$ values). Univariate linear regression analysis was used to look for linear correlations between continuous variables (Pearson's correlation coefficient (R)). Chi square tests were used to examine the incidence of abnormalities.

\section{Results}

CLINICAL FINDINGS (TABLE 1)

Seven patients had systolic murmurs, two of which were associated with mitral valve clicks. Systolic blood pressure was significantly higher than control values in the study group: median, 121 (range, 96-148) $\mathrm{mm} \mathrm{Hg} v 102$ (90110) $\mathrm{mm} \mathrm{Hg}(\mathrm{p}=0.004)$, and four patients had systolic blood pressures $>130 \mathrm{~mm} \mathrm{Hg}$. However, diastolic blood pressures were normal and similar to control values $(\mathrm{p}=0.7)$.

ELECTROCARDIOGRAPHY (TABLE 1)

All patients were in sinus rhythm with a normal $P$ wave axis. Three patients had first degree heart block, with a P-R interval between 240 and $340 \mathrm{~ms}$; four patients had a borderline $\mathrm{P}-\mathrm{R}$ interval $(200 \mathrm{~ms})$; and in only five patients was the $\mathrm{P}-\mathrm{R}$ interval unequivocally normal. Two patients had left axis deviation (45 and $50^{\circ}$ ); in one patient this was associated with minor QRS prolongation (160 ms), and the other patient exhibited abnormal QRS progression in the anterior chest leads. Another patient had QRS prolongation (140 ms) associated with first degree heart block but normal QRS morphology. One further patient had incomplete right bundle branch block but had normal QRS duration. No patient had ECG evidence of ventricular hypertrophy and there were no significant repolarisation abnormalities. Conduction defects were more common in the older patients.

On 24 hour Holter monitoring, the minimum heart rate was $<40$ beats $/ \mathrm{min}$ in four patients (32-39 beats/min), two of whom had first degree heart block, and it was between 40 and 50 beats/min in two others (one with first degree heart block). However, no patient exhibited significant pauses, and no tachyarrhythmias were detected. 
Table 2 Echocardiographic findings

\begin{tabular}{llll}
\hline & Patients & Controls & p Value \\
\hline LVDD $(\mathrm{cm})$ & $4.06(3.25-5.22)$ & $4.44(3.63-4.72)$ & 0.64 \\
SF $(\%)$ & $37(26-45)$ & $38(30-46)$ & 0.21 \\
PWD $(\mathrm{cm})$ & $0.74(0.5-0.95)$ & $0.70(0.56-0.88)$ & 0.08 \\
HR $($ beats/min) & $68(58-97)$ & $81(70-92)$ & 0.008 \\
IVRT $(\mathrm{ms})$ & $74(59-98)$ & $61(51-64)$ & 0.004 \\
E (m/s) & $0.82(0.7-1.16)$ & $0.78(0.7-0.86)$ & 0.05 \\
A (m/s) & $0.44(0.35-0.64)$ & $0.46(0.42-0.49)$ & 0.33 \\
E/A ratio & $1.83(0.52-3.2)$ & $1.67(1.65-1.86)$ & 0.13 \\
EAccT $(\mathrm{ms})$ & $88(72-98)$ & $77(68-80)$ & 0.006 \\
EDecT $(\mathrm{ms})$ & $129(100-174)$ & $123(108-133)$ & 0.05 \\
\hline
\end{tabular}

Values are median (range).

^Wilcoxon's.

LVDD, left ventricular (LV) diastolic diameter; SF, fractional shortening; PWD, diastolic posterior wall thickness; HR, heart rate; IVRT, isovolumic relaxation time; E, peak early filling velocity; A, peak atrial phase filling velocity; E/A ratio, E/A; EAccT and EDecT, time to and from peak E velocity, respectively. even in the absence of clinical or systolic functional evidence of myocardial abnormality.

Left ventricular function in myotonic dystrophy has been examined using a variety of echocardiographic techniques. ${ }^{25} 26$ Other authors have also noted a high incidence of mitral valve prolapse, ${ }^{25}{ }^{27}$ which probably reflects papillary muscle dysfunction. Although pronounced mitral regurgitation will alter transmitral flow characteristics, ${ }^{22}$ no patient had more than mild regurgitation on colour flow Doppler examination. In addition, the abnormalities of diastolic filling were neither confined to nor most severe in the three patients with mitral valve prolapse.

Our study is in agreement with most others in that abnormalities of systolic function are rare, except as a late and often terminal event. ${ }^{11252628}$ The mildly reduced SF in three patients might have future relevance or might simply reflect increased afterload ${ }^{29}$ related to slightly higher than normal blood pressure. Afterload can also cause prolongation of IVRT $^{30}$ but has little effect on the remainder of diastolic filling. Although systolic blood pressure was mildly elevated in four patients at the time of study, diastolic pressures were generally normal and of the two patients with posterior wall thickness $>90$ th centile for BSA, only one had raised systolic pressure at the time of study. Systolic pressure is particularly labile in young people but because heart rates were generally subnormal, excessive arousal is unlikely to have greatly confounded the results of our study.

Diastolic filling patterns are very heart rate dependent but this mainly affects the atrial contribution to left ventricular filling - that is, the peak $\mathrm{A}$ velocity and the $\mathrm{E} / \mathrm{A}$ ratio. ${ }^{22}{ }^{31}$ Atrial phase filling was relatively normal in our study group, where the principal abnormalities were of early diastolic filling. Stewart and colleagues $^{31}$ reported a $2-4 \%$ increase in peak E velocity for each 10 beats/min reduction in heart rate, as well as prolongation of IVRT, so that the $10-14 \%$ differences noted here probably require additional explanation.

A number of earlier studies examined rates of diastolic LV wall motion from digitised $M$ mode echocardiograms, ${ }^{75}{ }^{32}$ with rather inconsistent results. Abnormalities of rates of wall motion do not necessarily correlate with those of transmitral flow patterns and comparisons with these studies are unhelpful.

Nguyen et $a l,{ }^{28}$ in their histological study of the cardiac conduction system in myotonic dystrophy, noted a high incidence of myocyte hypertrophy in their specimens, with a variable degree of fibre disarray and interstitial fibrosis, as well as chamber dilatation in some patients. The abnormalities of diastolic filling found in our study are compatible with a mixed picture of myocyte hypertrophy and fibrosis, with delayed onset but rapid early diastolic filling in the presence of a relatively normal atrial phase. ${ }^{1922} 29$

It is possible that some abnormalities of diastolic filling might be related to intraventricular conduction defects and perhaps incoordinate myocardial activation. These patients
Children and young adults with congenital myotonic dystrophy exhibit noteworthy abnormalities of left ventricular diastolic function, 
exhibited many of the classic electrocardiographic features of myotonic dystrophy, ${ }^{56}$ but there were no significant correlations between the measured ECG intervals and diastolic filling times. Neither were there any significant associations between the presence of diastolic and conduction abnormalities.

We did not attempt to correlate severity of motor impairment and myocardial dysfunction in this small study, but ECG abnormalities and arrhythmias are generally recognised to be more severe in those with worse musculoskeletal difficulties. ${ }^{56}$ Xie et al reported a worse prognosis in adults with congestive cardiac failure and diastolic abnormalities including an $\mathrm{E} / \mathrm{A}$ ratio of 2, possibly as a result of an increase of left atrial pressure associated with severely abnormal diastolic function. ${ }^{18}$ Five of our patients had an E/A ratio of $\geqslant 2$ (in two patients the $\mathrm{E} / \mathrm{A}$ ratio was $>3$ ), but these patients were not otherwise readily distinguishable from their peers. It is quite possible that occult diastolic dysfunction might predispose to the rapid clinical decompensation associated with the haemodynamic stresses of severe exertion, pregnancy, or anaesthesia in patients with myotonic dystrophy. Therefore, abnormalities of transmitral Doppler flow patterns might be of prognostic relevance in these patients but longer term studies are clearly needed.

CONCLUSIONS

Young patients with congenital myotonic dystrophy exhibit evidence of myocardial dysfunction as well as conduction disturbance. Diastolic abnormalities suggestive of both abnormal myocyte relaxation and tissue compliance are detectable by Doppler echocardiography, and are associated with systolic dysfunction in some patients. Such abnormalities might be associated with an increased risk of symptomatic decompensation, particularly under haemodynamic stress, but such prognostic implications require further study. Regular electrocardiographic monitoring of patients with myotonic dystrophy is already advocated in view of the risks of both bradyarrhythmias and tachyarrhythmias. ${ }^{46}$ Assessment of left ventricular diastolic filling patterns may also be relevant.

1 Harley HG, Rundle SA, Reardon W, et al. Unstable DNA sequence in myotonic dystrophy. Lancet 1992;339:1125-8.

2 Harper PS. The genetics of muscular dystrophy. Prog Med Genet 1985;6:53-90.

3 Harper PS. Congenital myotonic dystrophy in Britain. Arch Dis Child 1975;50:505-13.

4 Hawley RJ, Milner MR, Gottdiener JS, Cohen A. Myotonic heart disease: a clinical follow-up. Neurology 1991;41:25962 .

5 Forsberg H, Olofsson BO, Eriksson A, Andersson S. Cardiac involvement in congenital myotonic dystrophy. $\mathrm{Br}$ Heart F 1990;63:119-21

6 Fragola PV, Autore C, Magni G, Antonini G, Picelli A Cannata D. The natural course of cardiac conduction disturbances in myotonic dystrophy. Cardiology 1991;79:93-8.

7 Perloff JK, Stevenson WG, Roberts NK, Cabeen W, Weiss J. Cardiac involvement in myotonic muscular dystrophy (Steinert's disease): a prospective study of 25 patients. Am $\mathcal{f}$ Cardiol 1984;54:1074-81.
8 Pickering JG, Guiraudon C, Klein GJ. Focal right atrial dysplasia and atrial flutter in a patient with myotonic dystrophy. Pacing Clin Electrophysiol 1989;12:1317-23.

9 Grigg LE, Chan W, Mond HG, Vohra JK, Downey WF. Ventricular tachycardia and sudden death in myotonic dystrophy: clinical, electrophysiologic and pathologic features. $\mathcal{F}$ Am Coll Cardiol 1985;6:254-6.

10 Hromasa S, Ikeda T, Kubota K, et al. Ventricular tachycardia and sudden death in myotonic dystrophy. Am Heart $\mathcal{F}$ 1988;115:914-15

11 Lin AE, Mitchell FM, Fitz RW, Doyle JJ. Dilated cardiomyopathy in myotonic dystrophy [letter]. $\mathcal{F}$ Am Coll Cardiol 1989;13:262-3.

12 Dodds TM, Haney MF, Appleton FM. Management of peripartum congestive heart failure using continuous arteriovenous hemofiltration in a patient with myotonic dystrophy. Anesthesiology 1991;75:907-11.

13 Fall LH, Young WW, Power JA, Faulkner CS, Hettleman $\mathrm{BD}$, Robb JF. Severe congestive cardiac failure and cardiomyopathy as a complication of myotonic dystrophy in pregnancy. Obstet Gynecol 1990;76:481-5.

14 Mudge BJ, Taylor PB, Vanderspek AF. Perioperative hazards in myotonic dystrophy. Anaesthesia 1980;35:492-5.

15 Reardon W, Newcombe R, Fenton I, Sibert J, Harper PS. The natural hsitory of congenital myotonic dystrophy, mortality and long term clinical aspects. Arch Dis Child 1993;68:177-81.

16 Cohn JN, Johnson G. Heart failure with normal ejection fraction: the V-HeFT study. Circulation 1990;81(suppl III): $48-53$

17 Lin SL, Tak T, Kawanishi DT, McKay CR, Rahimtoola SH, Chandraratna PA. Comparison of Doppler echocardiographic and hemodynamic indexes of left ventricular diastolic properties in coronary artery disease. Am 7 Cardiol 1988;62:882-6.

18 Xie GY, Berk MR, Smith MD, Gurley JC, DeMaria AN. Prognostic value of Doppler trans-mitral flow patterns in patients with congestive heart failure. $7 \mathrm{Am}$ Coll Cardiol 1994;24:132-9.

19 Maron BJ, Spirito P, Green KJ, Wesley YE, Bonow RO, Arce J. Non-invasive assessment of left ventricular diastolic function by pulsed Doppler echocardiography in patients with hypertrophic cardiomyopathy. 7 Am Coll Cardiol 1987; with hypert

$20 \mathrm{Lau}$ KC, Li AMC, Yeung CY. Left ventricular function in B thalassaemia major. Arch Dis Child 1989;64:1046-54.

21 Sampson MJ, Chambers JB, Sprigings DC, Drury PL. Abnormal diastolic function in patients with type 1 diabetes and early nephropathy. Br Heart f 1990;64:22671.

22 Nishamura RA, Tajik AJ. Evaluation of diastolic filling of the left ventricle in health and diasease: Doppler echocardiography is the clinician's Rosetta stone. $\mathcal{f}$ Am Coll Cardiol 1997;30:8-18.

23 Bu'Lock FA, Mott MG, Martin RP. Left ventricular diastolic function in children measured by Doppler echocardiography: normal values and relation with growth. Br Heart f 1995; 73:334-9.

24 Bu'Lock FA, Mott MG, Oakhill A, Martin RP. Left ventricular diastolic function after anthracycline chemotherapy in childhood: relation with systolic function, symptoms and pathophysiology. Br Heart f 1995;73:340-50.

25 Gottdeiner JS, Hawley RJ, Gay JA, DiBianco R, Fletcher $\mathrm{RD}$, Engel WK. Left ventricular relaxation, mitral valve prolapse and intracardiac conduction in myotonia atrophica: assessment by digitised echocardiography and non-invasive His bundle recording. Am Heart $\mathcal{F} 1982 ; 104$ : non-invasi

26 Badano L, Autore C, Fragola PV, et al. Left ventricular myocardial function in myotonic dystrophy. Am $\mathcal{f}$ Cardiol 1993;71:987-91.

27 Streib EW, Meyers DG, Sun SF. Mitral valve prolapse in myotonic dystrophy. Muscle Nerve 1985;8:650-3.

28 Nguyen HH, Wolfe JT, Holmes DR, Edwards WD. Pathology of the cardiac conduction system in myotonic dystrophy: a study of 12 cases. F Am Coll Cardiol 1988;11: 662-71.

29 Appleton CP, Hatle LK, Popp RL. Relation of transmitral flow velocity patterns to left ventricular diastolic function: new insights from a combined hemodynamic and Doppler echocardiographic study. $7 \mathrm{Am}$ Coll Cardiol 1988;12:42640.

30 Smith SA, Stoner JE, Russell AE, Sheppard JM, Aylward PE. Transmitral velocities measured by pulsed Doppler in healthy volunteers: effects of acute changes in blood pressure and heart rate. Br Heart $\mathcal{F}$ 1989;61:344-7.

31 Stewart RAH, Joshi J, Alexander N, Nihoyannopoulous P, Oakley CM. Adjustment for the influence of age and heart rate on Doppler measuremnets of left ventricular filling. $\mathrm{Br}$ Heart $\mathcal{F}$ 1992;68:608-12.

32 Reeves WC, Griggs R, Nanda NC, Thomson K, Gramiak R. Echocardiographic evaluation of cardiac abnormalities in Duchenne's dystrophy and myotonic muscular dystrophy. Arch Neurol 1980;37:273-7. 